\section{Free chairside support for implant test drive}

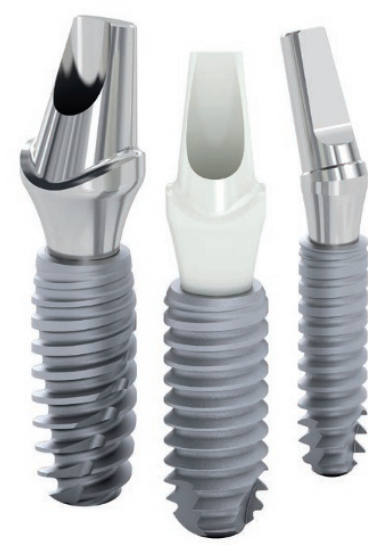

Clinicians keen to try the Axiom implant system for themselves can expect free chairside support from an Anthogyr representative for their first case. The no obligation test drive underlines the confidence the company has in its high-performing and commercially attractive implant system.

Your Anthogyr representative provides everything needed to treat your first Axiom case and remains with you throughout the procedure to give product advice.

Anthogyr's portfolio of world-class products is at the cutting edge of implant dentistry. All Axiom implants benefit from common characteristics, including a strong, conical connection and platformswitching for more predictable and aesthetic outcomes. The sand-blasted neck optimises bone anchorage, while surface threading provides efficient bone stimulation. The implants are manufactured from grade $\mathrm{V}$ medical titanium and have a $\mathrm{BCP}$ osteo-conductive surface for biocompatibility. The surgical and restorative kits are easy to use and time saving.

Dental technicians can also benefit from one-to-one support from their Anthogyr representative. Simeda is a comprehensive and flexible range of CAD/CAM and prosthetics, compatible with most implant systems.

www.anthogyr.com.

\section{The height of good taste}

As a result of a medical condition or due to the ageing process, many patients experience a lack or loss of taste sensation. This has the potential to impact negatively on the health and wellbeing of patients and metal in the mouth can often compound these problems.

For an effective alternative to metal discover Ultaire AKP from Solvay Dental 360. This new generation of material has been exclusively developed for removable partial denture (RPD) frames and offers taste-free comfort.

The distinguishing benefit of Ultaire AKP is that it has a bone-like feel that your

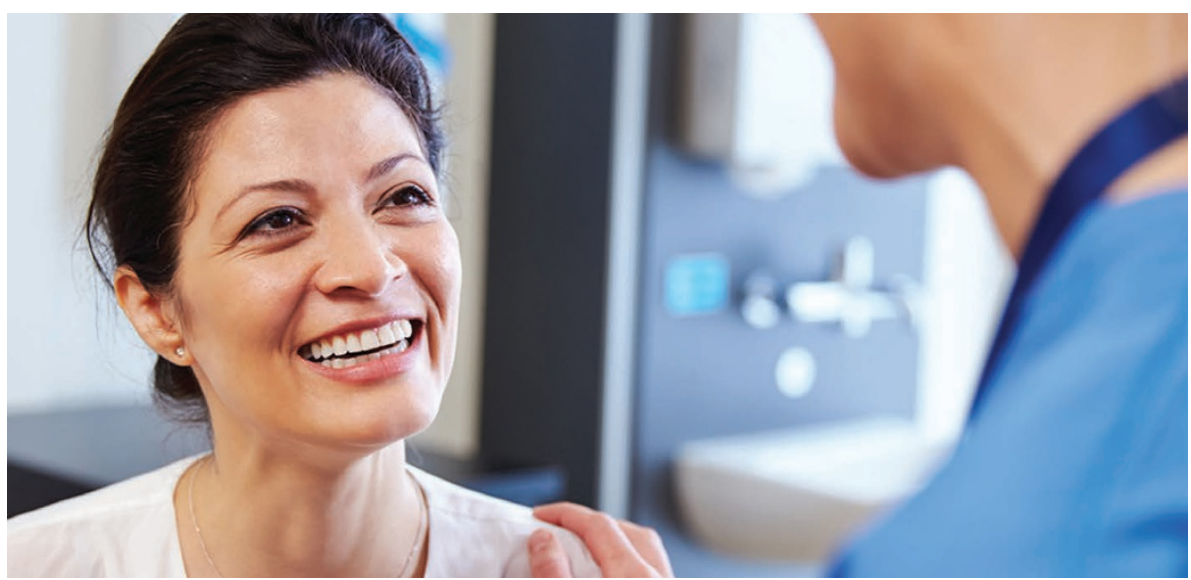

\section{A revolution in gum health}

Scientifically developed by the founder of The California Breath Clinics, dentist and internationally acclaimed 'Bad Breath Guru' Dr Harold Katz, the new The Breath Company Healthy Gums Oral Rinse, $£ 14$ for $500 \mathrm{ml}$, is formulated for patients to use in their daily oral care routine to support and maintain healthy gums.

The Breath Company Healthy Gums Oral rinse is packed with actives proven to support and promote gum health. Formulated with an ingredient proven to fight gum disease it works in two ways by eliminating the germs associated with gum disease and reducing the formation of biofilm which leads to plaque and tartar build-up.

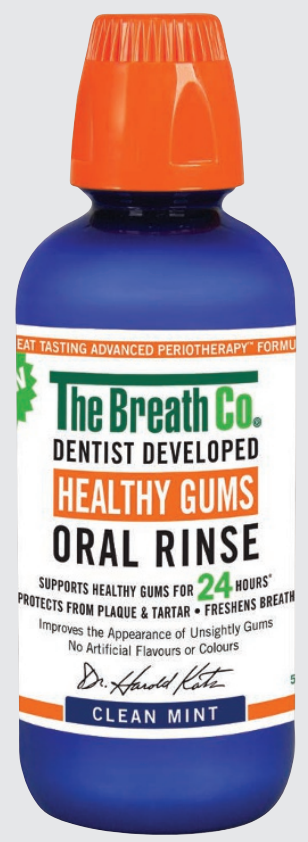

Used twice a day, this oral rinse will rapidly improve healthy gum appearance and provide relief from bleeding and sensitivity caused by gingivitis. Approved for use by diabetics and pregnant and nursing mums, it is gluten free, vegan and Kosher.

To use the Oral Rinse, shake well before use then rinse the mouth for one minute with one capful. Gargle with another capful for 30 seconds to clean your throat, and wait five minutes before eating. Use morning and night.

The Breath Company Gums Oral Rinse, $£ 14$ for $500 \mathrm{ml}$, is available from Boots stores nationwide and www.boots.com. 